\title{
Education Research: Resident education through adult learning in neurology
}

\section{Implementation and impact}

Hazem Shoirah, MD,* Achilles Ntranos, MD,* Rachel Brandstadter, MD, Yangbo Liu, MS, Elisha Medina, MS, Jamie Kwan, BS, and Stephen Krieger, MD

Neurology ${ }^{\circledR}$ 2018;91:234-238. doi:10.1212/WNL.0000000000005914
Correspondence Dr. Shoirah hazem.shoirah@ mountsinai.org

\section{Abstract}

\section{Objective}

To enhance residency education by implementing the 6 principles of adult learning theory (ALT) in a large academic neurology residency program.

\section{Methods}

We implemented a set of curricular interventions aimed at Resident Education through Adult Learning in Neurology (REAL Neurology), in a large, academic neurology residency program. Interventions included didactic reform, increasing resident-as-teacher activities, and enhancing residents' interaction. The primary outcome was the change in mean Residency In-service Training Examination (RITE) percentile between the preintervention and postintervention cohorts, adjusting for US Medical Licensing Examination step 1 and 2 score. Other analysis included evaluating the effect of the duration of intervention exposure on outcome and evaluating the intervention effect on the proportion of advanced performers.

\section{Results}

A total of 134 RITE score reports were evaluated (87 preintervention and 47 postintervention). The mean RITE score percentile postintervention was 11.7 points higher than preintervention (adjusted, longitudinal analysis: fit linear mixed model, $p<0.0001$ ). Postgraduate year 3 learners who had 1 and 2 years of exposure scored 13.4 and 18.9 points higher than those with no exposure at all, respectively (analysis of covariance, $p=0.04$ ). The adjusted odds of better performance with REAL Neurology was 5.77 (ordinal logistic regression, 95\% confidence interval 2.37-14.07, $p<0.05)$.

\section{Conclusion}

This study evaluated the efficacy and feasibility of an ALT-based curricular program in neurology education. The results show robust and sustainable benefit for residents in training without imposing a financial or logistical burden on programs. REAL Neurology could serve as a model for curricular reform in other programs across subspecialties. 


\section{Glossary}

AAN = American Academy of Neurology; ALT = adult learning theory; ANOVA = analysis of variance; GME = graduate medical education; PGY = postgraduate year; REAL Neurology = Resident Education through Adult Learning in Neurology; RITE = Residency In-service Training Examination; USMLE = US Medical Licensing Examination.

There is well-deserved emphasis on remodeling graduate medical education (GME) programs to develop the role of residents as teachers. The American Council for Graduate Medical Education recognized the importance of wellstructured, goal-oriented educational curricula with the introduction of the educational milestones. ${ }^{1}$ Solid foundation in the philosophy of learning is necessary for such programs to be efficacious and sustainable in an ever-changing health care system.

Many learning theories have been incorporated into medical education. ${ }^{2}$ Perhaps most notable is Malcolm Knowles' pivotal adult learning theory (ALT). ${ }^{3}$ Knowles proposed 6 characteristics that distinguish adult learning from pedagogy, those being readiness, self-directedness, internal motivation, relevance, goal orientation, and implementation of life experiences. Knowles' framework has spurred educational research and expanded the educational initiatives for adult learners in medicine. ${ }^{4-6}$ Even so, there are scarce data about ALT-based educational curricula in GME programs generally, and in neurology specifically.

We hypothesized that the implementation of ALT-based curriculum is an effective and feasible intervention to enhance residency education and improve objective measures of residents' knowledge. We utilized change in Residency In-service Training Examination (RITE) scores as our primary outcome.

\section{Methods}

\section{Study population}

Neurology residency in the United States is a 3-year advanced training program of postgraduate year (PGY) 2 through 4 residents. Our program is at a large academic center that expanded during the study period, resulting in 6-8 residents per PGY class for a total of 18-24 residents. Performance of all residents on the annual RITE was divided based on the year of curricular implementation into preintervention and postintervention cohorts (2010-2014 and 2015-2016, respectively). The study was reviewed and exempted by the local institutional review board.

\section{Intervention}

Prior to program implementation in 2015, the residency educational curriculum was delivered in a series of 60-minute didactic sessions, the format and content of which was shaped by faculty educators' experience and preference. There was no formal teaching role for residents. Resident Education through Adult Learning in Neurology (REAL Neurology) is a resident-led ALT-based curricular reform, designed by the authors based on their educational experience, in collaboration with the stakeholders in faculty and learners. The objective of the program is to recalibrate the educational process towards the learners, by implementing 3 prespecified ALTbased interventions: didactic reform, enhancing the residents' teaching roles, and increasing resident engagement in educational activities (table).

\section{Outcome assessment tools}

Our primary outcome was RITE performance. The RITE is an annual self-assessment tool developed by the American Academy of Neurology (AAN) to gauge resident knowledge of neurology and neuroscience and identify areas for potential growth. ${ }^{7}$ Results are reported as percentiles comparing each resident's performance to PGY-matched nationwide testtakers.

\section{Statistical methods}

A linear mixed model was fitted with RITE percentiles as the outcome and curricular intervention as fixed effect, after adjusting for residents' US Medical Licensing Examination (USMLE) step 1 and 2 scores, using $F$ test, with $\alpha$ level set to $5 \%$. Kolmogorov-Smirnov test was used to confirm the normal distribution of RITE and USMLE scores $(p>0.05)$. We accounted for within-subject correlation using longitudinal analysis. We imputed missing data with available case analysis. We assessed baseline USMLE scores of the residents by oneway analysis of variance (ANOVA) and $t$ test. The correlation of USMLE scores to RITE scores was evaluated by Pearson correlation. We further categorized RITE performance outcome into advanced ( $>75$ th percentile), average (25th-75th percentile), and poor ( $<25$ th percentile). We assessed category proportions by ordinal logistic regression after adjusting for USMLE step 1 and step 2 scores. Finally, to assess the effect of accumulative exposure to the intervention, we performed a subgroup analysis of outcome of 24 learners; 8 from each of 3 consecutive PGY3 classes (2014-2016). As the intervention was implemented in 2015, they had 0, 1, or 2 years of exposure to the new curriculum. An adjusted linear model was fitted with years of exposure to intervention as covariate, and type III analysis of effects was reported. All analyses were performed using SAS version 9.4 (SAS Institute, Cary, NC).

\section{Results}

\section{Baseline characteristics}

There were 134 RITE score reports: 87 in the preintervention and 47 in the postintervention cohort. The mean USMLE 
Table Resident Education through Adult Learning in Neurology (REAL Neurology) interventions

\begin{tabular}{|c|c|c|c|}
\hline & ALT principles & Previous program & REAL Neurology \\
\hline \multirow[t]{5}{*}{ Didactic reform } & $\begin{array}{l}\text { - Relevance: Use of clear aims to } \\
\text { foster motivation in the adult learner }\end{array}$ & $\begin{array}{l}\text { - Didactic objectives set by } \\
\text { leadership }\end{array}$ & $\begin{array}{l}\text { - Objectives revisited via leadership } \\
\text { and residents' collaboration }\end{array}$ \\
\hline & $\begin{array}{l}\text { - Goal-directedness: The desire to } \\
\text { immediately apply knowledge } \\
\text { towards career goals, such as better } \\
\text { patient care and academic } \\
\text { performance }\end{array}$ & $\begin{array}{l}\text { - Content based on experience } \\
\text { and preference of educators }\end{array}$ & $\begin{array}{l}\text { - Content prioritized by clinical } \\
\text { relevance }\end{array}$ \\
\hline & & $\begin{array}{l}\text { - Sessions organized by month } \\
\text { subspecialty blocks }\end{array}$ & $\begin{array}{l}\text { - Sessions organized by escalating } \\
\text { sophistication, matching residents' } \\
\text { increasing acumen of knowledge }\end{array}$ \\
\hline & & & $\begin{array}{l}\text { - Preservation of the total didactic } \\
\text { hours without adding educational } \\
\text { time }\end{array}$ \\
\hline & & & $\begin{array}{l}\text { - Curricular overview and didactic } \\
\text { session list disseminated to residents } \\
\text { in written format }\end{array}$ \\
\hline \multirow[t]{5}{*}{$\begin{array}{l}\text { Enhancing resident } \\
\text { engagement }\end{array}$} & $\begin{array}{l}\text { - Self-directedness: Creation of } \\
\text { a teaching environment that best } \\
\text { engages adult learners and utilizes an } \\
\text { atmosphere of mutual respect, trust, } \\
\text { and collaboration }\end{array}$ & $\begin{array}{l}\text { - } 60 \text {-minute daily faculty-led } \\
\text { didactic session }\end{array}$ & $\begin{array}{l}\text { - Reduced the duration of didactic } \\
\text { sessions to } 40 \text { minutes }\end{array}$ \\
\hline & $\begin{array}{l}\text { - Implementation of life experiences: } \\
\text { The use of clinical experiences as } \\
\text { a foundation on which to add new } \\
\text { knowledge }\end{array}$ & & $\begin{array}{l}\text {-Introduced a daily 20-minute } \\
\text { interactive case-based discussion }\end{array}$ \\
\hline & & & $\begin{array}{l}\text { - Using interactive technology (e.g., } \\
\text { smartphone-based audience } \\
\text { response system) }\end{array}$ \\
\hline & & & $\begin{array}{l}\text { - Real-time session teleconferencing } \\
\text { with satellite hospitals with away } \\
\text { residents }\end{array}$ \\
\hline & & & - Online library of archived sessions \\
\hline \multirow[t]{5}{*}{ Resident-as-teacher } & $\begin{array}{l}\text { - Internal motivation: The intrinsic } \\
\text { drive of adults to learn and share } \\
\text { knowledge }\end{array}$ & $\begin{array}{l}\text { - Senior residents led informal } \\
\text { small groups for junior residents } \\
\text { and medical student teaching }\end{array}$ & $\begin{array}{l}\text { - A didactic session about residents as } \\
\text { teachers was introduced at the } \\
\text { beginning of the academic year }\end{array}$ \\
\hline & $\begin{array}{l}\text { - Readiness: Allows for teaching role } \\
\text { adoption which sets a strong impetus } \\
\text { for learning }\end{array}$ & & $\begin{array}{l}\text { - Introduced a dedicated } 6 \text {-week } \\
\text { "teaching service" with rotating PGY-4 } \\
\text { TR, covering } 48 \text { out of the } 52 \text { weeks of } \\
\text { the year }\end{array}$ \\
\hline & & & $\begin{array}{l}\text { - The TR prepared and led the daily } \\
\text { 20-minute interactive session }\end{array}$ \\
\hline & & & $\begin{array}{l}\text { - The TR presented lectures, } \\
\text { conducted simulation trainings and } \\
\text { courses on a variety of neurologic } \\
\text { topics for residents of other } \\
\text { departments }\end{array}$ \\
\hline & & & $\begin{array}{l}\text { - The TR continued to conduct small } \\
\text { teaching groups. }\end{array}$ \\
\hline
\end{tabular}

Abbreviations: $A L T=$ adult learning theory; $\mathrm{PGY}=$ postgraduate $y e a r ; \mathrm{TR}=$ teaching residents.

step 1 and step 2 scores for all learners in both cohorts was 227 (SD 15.9) and 239 (SD 15.86), respectively, with no difference between the academic years (one-way ANOVA, $p=$ 0.55 and 0.42 , respectively). USMLE step 1 and 2 scores correlated with residents' RITE percentiles at all PGY levels (Pearson correlation, USMLE step 1; PGY2: $R=0.61$, PGY3: $R=0.53$, and PGY4: $R=0.66, p<0.001$; USMLE step 2 ;
PGY2: $R=0.50$, PGY3: $R=0.49$, and PGY4: $R=0.60, p<$ $0.001)$.

\section{Primary outcome}

The mean RITE score percentile for the postintervention cohort was significantly higher than the preintervention cohort (68.3 vs 53.0, $p=0.0002$ ) (figure). This remained 
Figure The effect of Resident Education through Adult Learning in Neurology (REAL Neurology) curriculum on residentlearners' performance in the Residency In-service Training Examination (RITE)
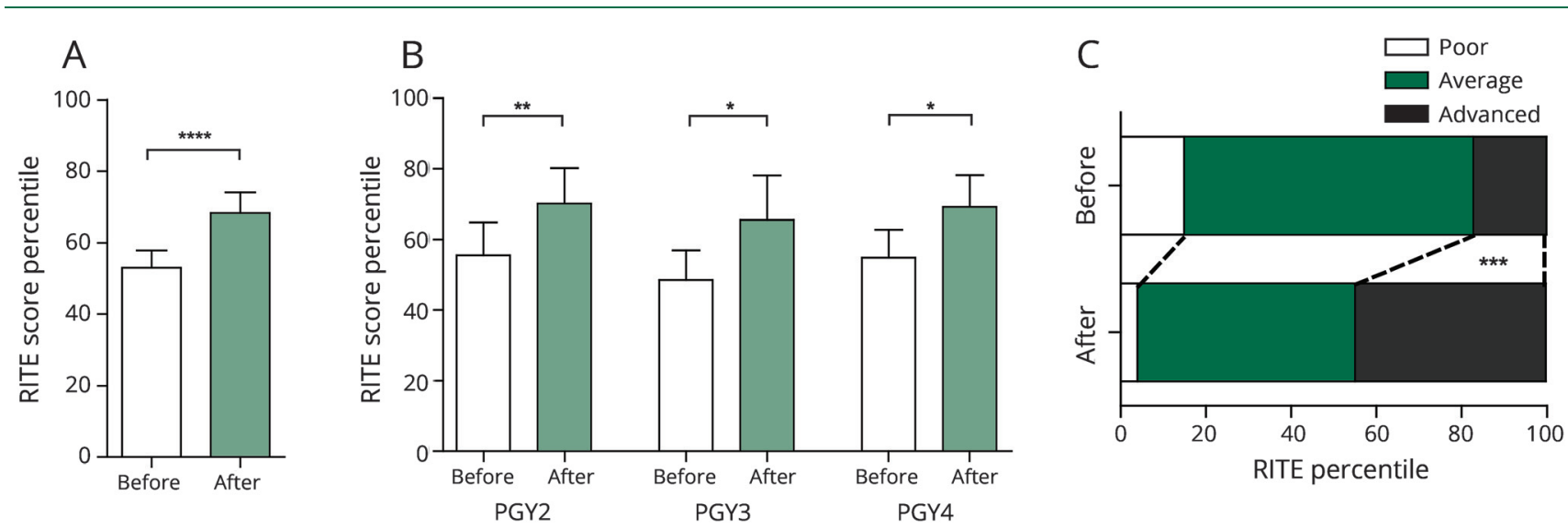

The RITE score percentiles in the pre and post REAL Neurology cohorts are shown. REAL Neurology significantly increased the mean RITE score percentile for all the postintervention learners together, even after adjusting for US Medical Licensing Examination (USMLE) Scores and repeated measures ( $p<0.0001)$ (A) as well as when comparing each postgraduate year (PGY) level separately and controlling for USMLE scores (PGY2: $p=0.00484 ; \mathrm{PGY3}: p=0.0192 ; \mathrm{PGY4}$ : $p=$ 0.030933). (B) The analysis of examination performance distribution based on RITE percentile (poor $<25$ th, average 25 th-75th, and advanced $>75$ th percentiles) reveals a significant shift towards higher performance after REAL neurology implementation (odds ratio 5.77, 95\% confidence interval [CI]

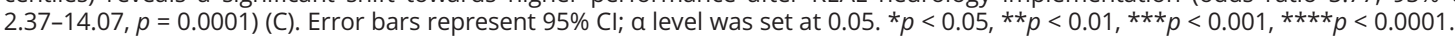

statistically significant after adjusting for USMLE scores and accounting for repeated measures (absolute difference 11.73, $p<0.0001)$. A similar significant difference was seen in each PGY class separately after adjusting for USMLE scores (PGY2: 70.1 vs 55.6, $p=0.00484$; PGY3: 65.6 vs 48.6, $p=$ 0.0192; PGY4: 69.2 vs 54.9, $p=0.030933$ ) (figure).

\section{Upward shift in examination performance}

Postintervention analysis revealed a significant increase in the proportion of residents with advanced performance and a corresponding reduction in average or poor performance (advanced: $44.7 \%$ vs $17.2 \%$, average: $51.0 \%$ vs $67.8 \%$, and poor: $4.0 \%$ vs $14.9 \%$ ) (ordinal logistic regression, adjusted odds 5.77 , 95\% confidence interval 2.37-14.07, $p=0.0001$ ) (figure).

\section{Positive accumulative impact of REAL Neurology}

In the subgroup of PGY3 learners, longer duration of exposure was associated with a higher RITE score percentile after controlling for USMLE scores. Residents who had 1 year (PGY3 in 2015) vs 2 years (PGY3 in 2016) of exposure respectively scored 13.4 and 18.9 percentiles higher than those who had no exposure at all (PGY3 in 2014) (analysis of covariance, $p=0.0357$ ).

\section{Discussion}

This study systemically evaluates the efficacy and feasibility of an ALT-based educational model. We found a clear and sustainable effect on objective educational outcomes at all PGY levels during training, which was augmented by longer exposure in a dose-dependent fashion. REAL Neurology did not simply expand the proportion of average learners at the expense of advanced learners. There was an upward learning shift into higher tiers of performance with the largest gain being in the advanced performance tier, which increased by more than double the baseline.

We chose RITE scores, a tool developed by the AAN for knowledge self-assessment, as our primary efficacy endpoint. RITE performance positively correlates with American Board of Psychiatry and Neurology pass rates in neurology. ${ }^{8}$ Juul et al. $^{8}$ estimated that scoring $<59$ th percentile on RITE was associated with $72 \%$ board pass rate, while scoring 65 th-69th percentile was associated with $98 \%$ board pass rate. The mean percentile of our residents increased from 53 to 68.3 after REAL Neurology implementation.

Any institutional change may be met with resistance. In our experience, this was mitigated by engaging all the educational stakeholders via strong collaboration between the residency program director and the chief resident of academic affairs. While residents' attitude about the curricular changes was not formally assessed, they expressed increased motivation and satisfaction on informal surveys.

We emphasize that this educational intervention was feasible. The knowledge necessary for curricular reform is available in academic workshops, open-source courses, or self-teaching. The technological upgrades in teleconferencing and audience response systems are available, often in free versions, utilizing ubiquitous smartphones. There was no change in total didactic time and no additional costs to the department (supplemental data, links.lww.com/WNL/A602).

Several limitations warrant specific discussion. Confounding factors may have affected the outcome, like learners' attitudes or awareness of the curricular reform process, which may 
result in increased self-study. This increased engagement could be both a confounder as well as an outcome of the intervention. Use of a case-control trial design could clarify these concerns. We used the preintervention cohort as a historic comparator as it was logistically prohibitive to divide the residents within the same program into 2 curricular cohorts. In addition, only 2 years of outcome data were available at the time of writing this manuscript. The effect on residents who were exposed to the intervention for the full 3 years of their training is unknown. The RITE measures knowledge acquisition in the Kirkpatrick hierarchy of educational outcomes, which is not the only objective of educational curricula. ${ }^{9}$ The intervention's effect on more advanced hierarchical domains, such as patient care or clinical outcomes, is unknown and could be explored in further studies. Finally, although the basic principles that went into this curricular reform are generalizable, this intervention was implemented in a single program of one specialty. Considerations for the design of future trials should include larger samples with contemporaneous control groups and representation from multiple specialties.

The cornerstone of this project is an implementation of the 6 principles of ALT, while engaging residents as leaders in education. For REAL Neurology, this specifically required a curricular refinement, a learner-focused session structure, and more resident teaching activities. REAL Neurology can potentially serve as model for other forms of resident-led ALT-based curricular reform.

\section{Author contributions}

Dr. Shoirah designed and administered the intervention, conducted the described research, coauthored the manuscript, and supervised the data analysis. Dr. Ntranos conducted and supervised the data analysis and coauthored the manuscript. Dr. Brandstadter administered the intervention and coauthored the manuscript. Y. Liu conducted the statistical analysis. Elisha Medina conducted data collection and entry. J. Kwan conducted data collection and entry. Dr. Krieger designed and conducted the described research and provided mentorship and supervision for the statistical analysis and manuscript writing including review, revision, and editing.

\section{Study funding}

No targeted funding reported.

\section{Disclosure}

The authors report no disclosures relevant to the manuscript. Go to Neurology.org/N for full disclosures.

\section{References}

1. Lewis SL, Józefowicz RF, Kilgore S, Dhand A, Edgar L. Introducing the neurology milestones. J Graduate Med Edu 2014;6:102-104.

2. Torre DM, Daley BJ, Sebastian JL, Elnicki DM. Overview of current learning theories for medical educators. Am J Med 2006;119:903-907.

3. Knowles MS, Holton EF III, Swanson RA. The Adult Learner: The Definitive Classic in Adult Education and Human Resource Development. 7 ed. New York: Routledge; 2011.

4. Hartzell JD. Adult learning theory in medical education. Am J Med 2007;120:e11.

5. Stahl SM, Davis RL. Applying the principles of adult learning to the teaching of psychopharmacology: overview and finding the focus. CNS Spectr 2009;14: 179-182.

6. Reed S, Shell R, Kassis K, et al. Applying adult learning practices in medical education. Curr Probl Pediatr Adolesc Health Care 2014;44:170-181.

7. Persaud L. RITE General Information [online]. aan.com. Accessed at: https://www. aan.com/tools-and-resources/residents-fellows/residency-in-service-training-examinationrite/. Accessed February 26, 2017.

8. Juul D, Flynn FG, Gutmann L, et al. Association between performance on neurology in-training and certification examinations. Neurology 2013;80:206-209.

9. Kirkpatrick DI, Craig RL, Bittel I, eds. Evaluation of Training. New York: Training and Development Handbook; 1967.

\section{Disputes \& Debates: Rapid online correspondence}

The editors encourage comments on recent articles through Disputes \& Debates:

Access an article at Neurology.org/N and click on "COMMENT" beneath the article header. Responses will be posted within 3 business days.

Before submitting a comment to Disputes \& Debates, remember the following:

- Disputes \& Debates is restricted to comments about studies published in Neurology within the last eight weeks

- Read previously posted comments; redundant comments will not be posted

- Your submission must be 200 words or less and have a maximum of five references; reference one must be the article on which you are commenting

- You can include a maximum of five authors (including yourself) 


\section{Neurology}

\section{Education Research: Resident education through adult learning in neurology: Implementation and impact}

Hazem Shoirah, Achilles Ntranos, Rachel Brandstadter, et al.

Neurology 2018;91;234-238

DOI 10.1212/WNL.0000000000005914

\section{This information is current as of July 30, 2018}

\section{Updated Information \& Services}

References

Citations

Subspecialty Collections

Permissions \& Licensing

Reprints including high resolution figures, can be found at: http://n.neurology.org/content/91/5/234.full

This article cites 6 articles, 1 of which you can access for free at: http://n.neurology.org/content/91/5/234.full\#ref-list-1

This article has been cited by 1 HighWire-hosted articles: http://n.neurology.org/content/91/5/234.full\#\#otherarticles

This article, along with others on similar topics, appears in the following collection(s):

\section{All Education}

http://n.neurology.org/cgi/collection/all_education

Computer use in education

http://n.neurology.org/cgi/collection/computer_use_in_education

Methods of education

http://n.neurology.org/cgi/collection/methods_of_education

Other Education

http://n.neurology.org/cgi/collection/other_education

Information about reproducing this article in parts (figures,tables) or in its entirety can be found online at:

http://www.neurology.org/about/about_the_journal\#permissions

Information about ordering reprints can be found online:

http://n.neurology.org/subscribers/advertise

Neurology ${ }^{\circledR}$ is the official journal of the American Academy of Neurology. Published continuously since 1951, it is now a weekly with 48 issues per year. Copyright () 2018 American Academy of Neurology. All rights reserved. Print ISSN: 0028-3878. Online ISSN: 1526-632X.

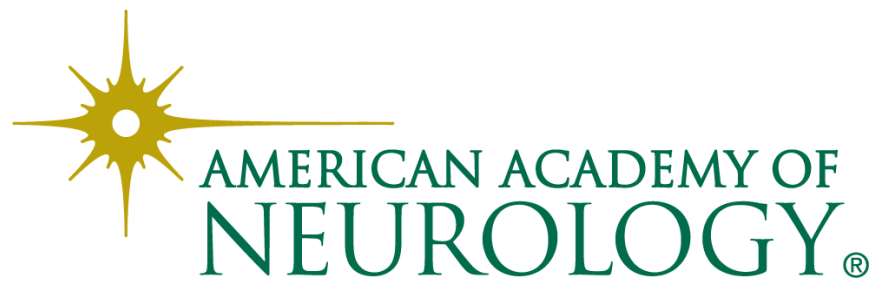

